\title{
Parametric Analysis of Friction Stir Welding on T-Joint of Aluminium Alloys Using Graphical Method
}

\author{
Authors

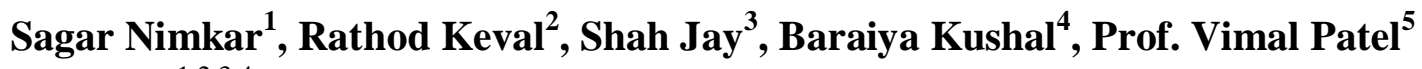 \\ ${ }_{1,2,3,4}$ Department of Mechanical Engineering, V.I.E.R, Vadodara, \\ ${ }^{5}$ Assistant Professor of Mechanical Engineering, V.I.E.R, Vadodara \\ Email-sagarnimkar95@yahoo.com,kevalr45@gmail.com,jshah820@gmail.com, \\ kushalbaraiya96@gmail.com,vm1310@gmial.com .
}

\begin{abstract}
In the present investigation we have worked on three Aluminum Alloy materials AA6000, AA6063 and AA6082respectively, at three different speed 1600rpm, 1700rpm and 1800rpm. And focusing on the three parameters temperature, viscosity and flow stress. For plotting the graphs, axis designation is the main factor and that has designated and results are presented. It has been observed the different behavior of the materials according to parameters at a different speeds.

Keywords: Friction Stir Welding, Temperature, Viscosity, Flow Stress, AA6000, AA6063, AA6082, T-Joint.
\end{abstract}

\section{INTRODUCTION}

Friction Stir Welding is a new welding technique for aluminum alloys invented by The Welding Institute, Cambridge, U.K. in 1991. This technique uses a non-consumable steel welding tool to generate frictional heating at the point of welding and to induce gross plastic deformation of work piece material while the material is in a solid phase, resulting in complex mixing across the joint. A detailed account of the process has been provided by others. Although Friction Stir Welding can be used to join a number of materials, the primary research and industrial interest has been to join aluminum alloys.

Friction stir welding technology has been demonstrated to produce very good and sound joints especially in the applications for light alloys. Based on friction heating at the faying surfaces of two sheets to be joined, in the FSW process a tool with a specially designed rotating probe travels down the length of contacting metal plates, producing a highly plastically deformed zone through the associated stirring action. The localized thermo-mechanical affected zone is produced by friction between the tool shoulder and the plate top surface, as well as plastic deformation of the material in contact with the tool occurs.

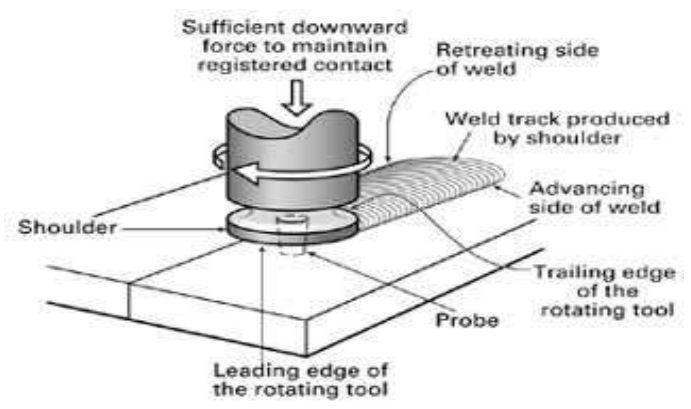

Fig: 1 Process figure

In FSW, a cylindrical-shouldered tool, with a profiled threaded/unthreaded probe (nib or pin) as shown Fig 1- is rotated at a constant speed and fed at a constant traverse rate into the joint line between two pieces of sheet or plate material, which are butted together. The parts have to be clamped rigidly onto a backing bar in a manner that prevents the abutting joint faces from being forced apart. The length of the nib is slightly less than the weld depth required and the tool shoulder should be in intimate contact with the work 
surface. The nib is then moved against the work, or vice versa.

Frictional heat is generated between the wearresistant welding tool shoulder and nib, and the material of the work pieces. This heat, along with the heat generated by the mechanical mixing process and the adiabatic heat within the material, cause the stirred materials to soften without reaching the melting point (hence cited a solidstate process), allowing the traversing of the tool along the weld line in a plasticized tubular shaft of metal. As the pin is moved in the direction of welding, the leading face of the pin, assisted by a special pin profile, forces plasticized material to the back of the pin while applying a substantial forging force to consolidate the weld metal. The welding of the material is facilitated by severe plastic deformation in the solid state, involving dynamic recrystallization of the base material.

FSW joints usually consist of four different regions as shown in Fig 2. They are: Aunaffected base metal, B- heat affected zone (HAZ), C-thermo-mechanically affected zone (TMAZ) and D-friction stir processed (FSP) zone. The formation of above regions is affected by the material flow behavior under the action of rotating non-consumable too.

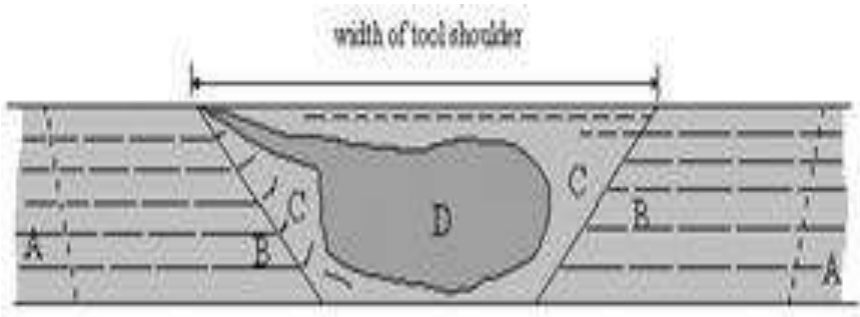

Fig: 2 - Different regions of FSW joint

\section{EXPERIMENTAL WORK AND RESULT}

The concept of graphs gives the clear vision of materials, properties and also their nature during the experimental work. The value used in this graphs were taken from the simulation work from named software.

Here, Aluminium Alloys series6000 were taken for the simulation work and from that series only three material i.e., AA6000, AA6063 and AA6082 resp. This worked on the three speed 1600rpm, 1700rpm and 1800rpm using circular tip profile tool. After simulations and getting results based on only three parameters such as "temperature", "viscosity" and "flow stress".

After the value evaluation, the need for plotting the graphs is axis designations. So in all the three main categories speed is taken on $\mathrm{X}$-axis and other three parameters on $\mathrm{Y}$-axis simultaneously. The graphs are categories on three parameters as "based on temperature", "based on viscosity" and "based on flow stress". Into that there is subcategory in each category by the three alloys materials.

\section{BASED ON TEMPERATURE:}

\section{AA6000:}

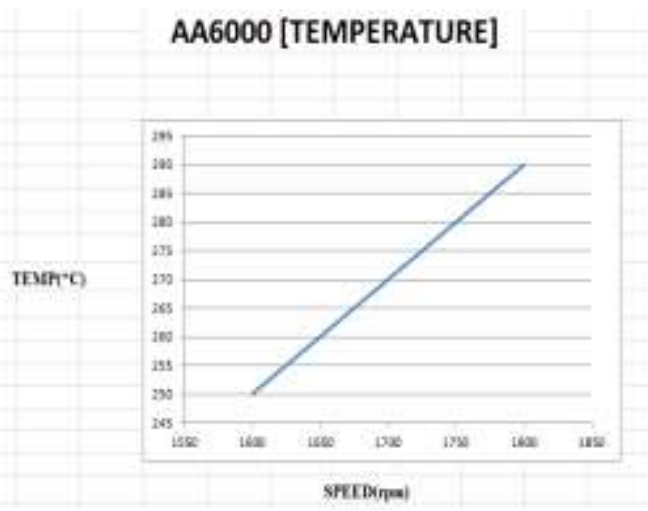

Fig: 3 Temperature graph on AA6000 AA6063:

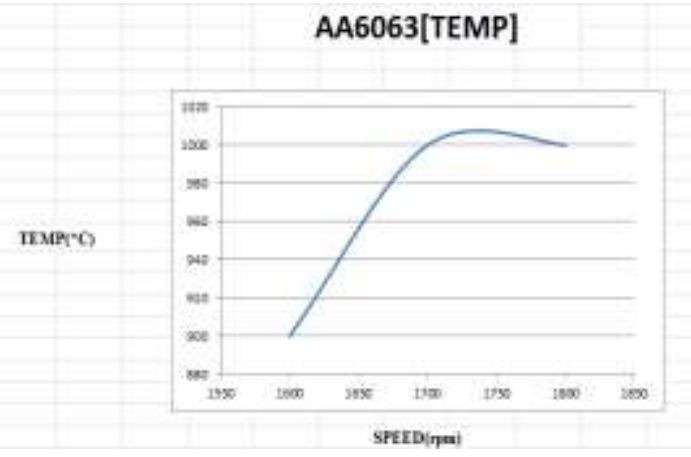

Fig: 4 Temperature graph on AA6063 AA6082:

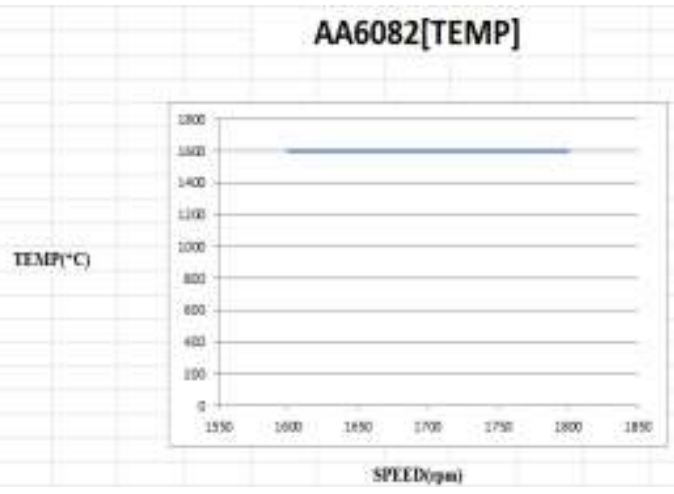

Fig: 5 Temperature graph on AA6082 
BASED ON VISCOSITY:

AA6000:

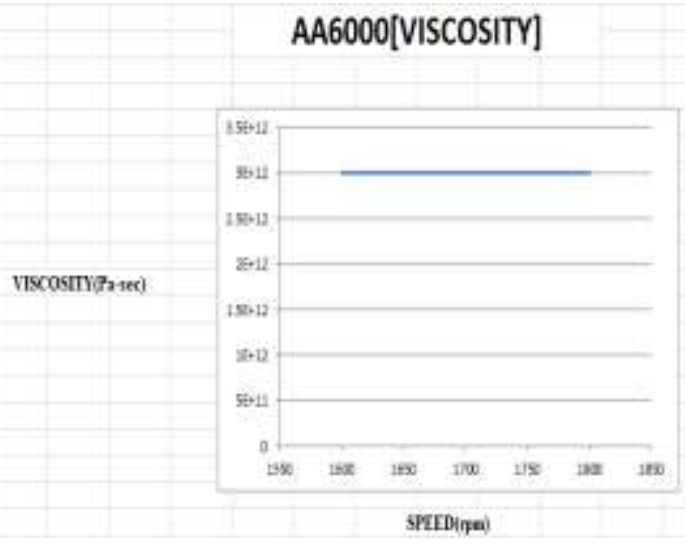

Fig: 6 Viscosity graph on AA6000

(B)AA6063:

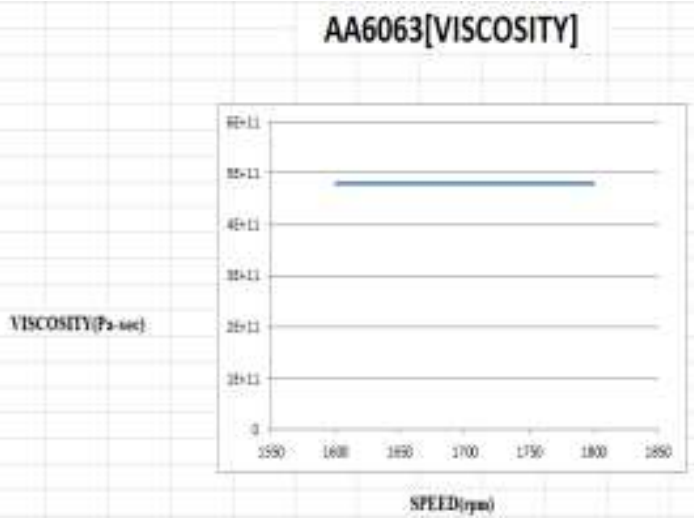

Fig: 7 Viscosity graph on AA6063

(C)AA6082:

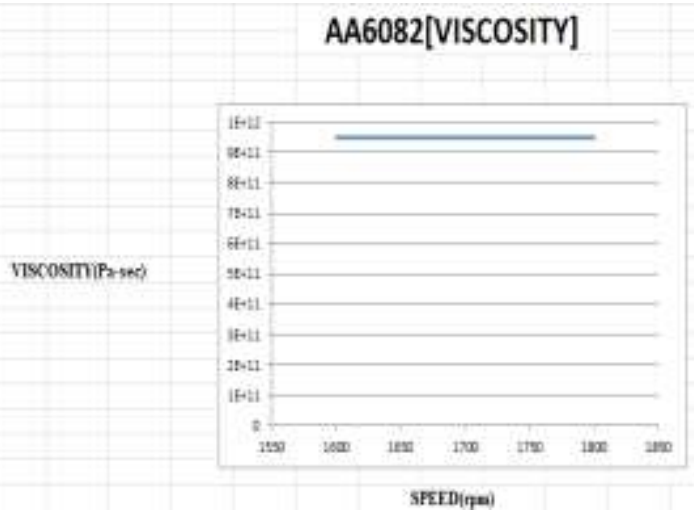

Fig: 8 Viscosity graph on AA6082

BASED ON FLOW STRESS:

(A)AA6000:

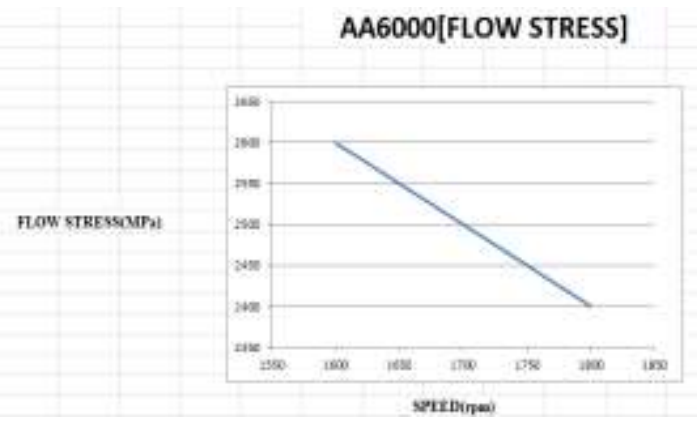

Fig: 9 Flow Stress graph on AA6000
(B)AA6063:

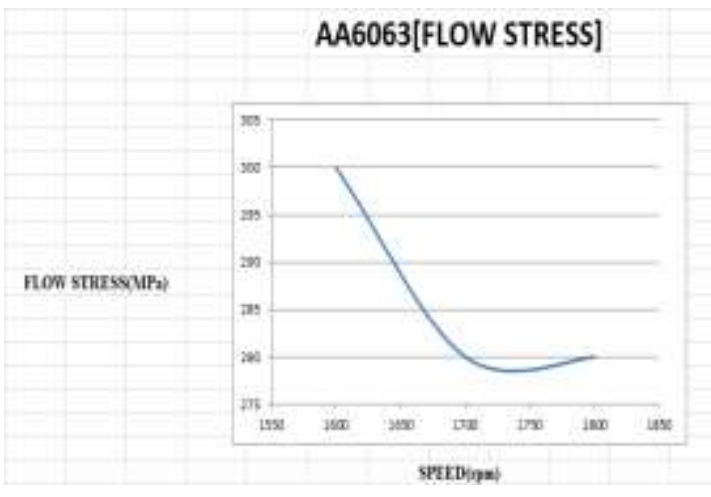

Fig: 10 Flow Stress graph on AA6063

(C)AA6082:

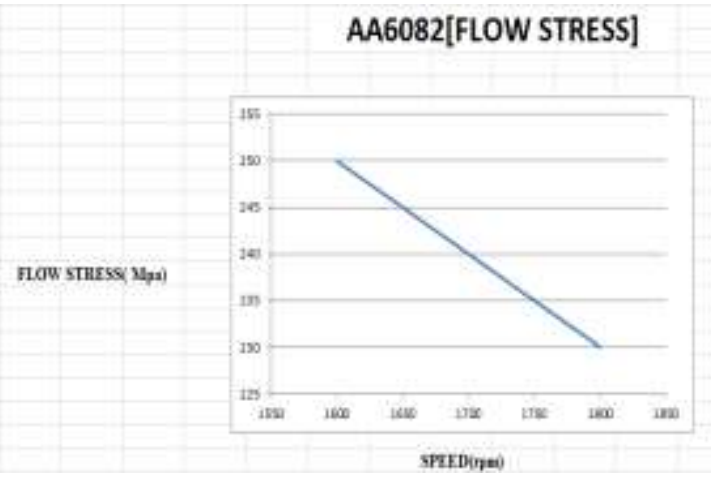

Fig: 11 Flow Stress graph on AA6082

\section{CONCLUSION}

Few points are concluded after plotting the graphs on the basis of three categories. Which are as follows below:

Based on temperature in all the common observation is temperature increases with increases in speed. In alloy material AA6000 the temperature increases gradually with constant rate, whereas in alloy material AA6063 temperature increases initially then remain constant. For alloy material AA6082 temperature remain constant throughout different speed.

Based on viscosity it is seen that changes in speed doesn't affect the value of viscosity for alloy material. For all the three alloys materials i.e. AA6000, AA6063, AA6082 respectively. The line remains constant.

Based on flow stress the results shows that the value decreases in all the three alloys materials. For material AA6000, the graphs fall on constant rates, for material AA6063, the line graphs decline at first and at last remain constant. Whereas for material AA6082, the graphs downfall as theconstant rates during entire different speed. 


\section{REFERENCES}

1. Comparison of Microstructure and Mechanical Properties of friction Stir welding of Al 6082 aluminum alloy with different Tool Profiles: Pavankumar Thimaraju, Krishnaiah Arkanti, G. Chandramohan Reddy, K.B.G.Tilak.

2. Double side friction stir welding of AA6082 sheets: Microstructure and nanoindentation characterization: M.Cabibo, A.Forecllese, M.El.Mehtedi, M.Simoncini.

3. Effect of the mutual position between weld seam and reinforcement on the residual stress distribution in Friction Stir Welding of AA6082 skin and stringer structures: G.Buffa, L.Fratini, G.Marannano, A.Pasta.

4. Corrosion susceptibility of dissimilar friction stir welds of AA5083 and AA6082 alloys: U.Donatus, G.E.Thompson, X.Zhou, J.Wang, A.Cassell, K.Beamesh.

5. Development of empirical relationships for prediction of mechanical and wear properties of AA6082 aluminum matrix composites produced using friction stir processing: I.Dinaharan, M.Murugan, A.Thangarasu.

6. Microstructure evolution and mechanical properties of dissimilar friction stir welded joints between AA1100-B ${ }_{4} \mathrm{C}$ MMC and AA6063 alloy: J.Guo, P.Gougeon, X.G.Chen.

7. Evaluation of the microstructure and wear behaviour of $\mathrm{AA} 6063-\mathrm{B}_{4} \mathrm{C} / \mathrm{TiB}_{2}$ mono and hybrid composite layers produced by friction stir processing: Mohammad Narimani, Behnam Lofti, Zohreh Sadeghian.

8. Microstructure and mechanical properties of friction stir welded AA6063-B ${ }_{4}$ C metal matrix composites: X.GChen, M.da. silva, P.Gougeon, L. st-George. 